\title{
Position Paper On Use Of Stereoscopy To Support Science Learning: Ten Years Of Research
}

\author{
C. Aaron Price, Museum of Science and Industry, Chicago, USA \\ Hee-Sun Lee, The Concord Consortium, Concord, USA \\ Julia D. Plummer, Pennsylvania State University, USA \\ Mark SubbaRao, Adler Planetarium, Chicago, USA \\ Ryan Wyatt, California Academy of Sciences, San Francisco, USA
}

\begin{abstract}
Stereoscopy's potential as a tool for science education has been largely eclipsed by its popularity as an entertainment platform and marketing gimmick. Dozens of empirical papers have been published in the last decade about the impact of stereoscopy on learning. As a result, a corpus of research now points to a coherent message about how, when, and where stereoscopy can be most effective in supporting science education. This position paper synthesizes that research with examples from three studies recently completed and published by the authors of this paper. Results of the synthesis point towards generally limited successful uses of stereoscopic media in science education with a pocket of potentially beneficial applications. Our position is that stereoscopy should be used only where its unique properties can accommodate specific requirements of understanding topics and tasks-namely visualizations where the spatial sense of depth is germane to conveying core ideas and cognitive load is high. Stereoscopy's impact on learning is also related to the spatial ability of the viewer. More research is needed on the effect of novelty, longterm learning and possible learning differences between the various methods of implementing stereoscopy.
\end{abstract}

Keywords: Astronomy Education; Stereoscopy; Spatial Cognition; Science Visualizations

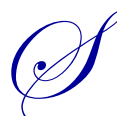

tereoscopic technology has been around for almost two centuries. Yet its potential as a tool for science education has been largely eclipsed by its popularity as an entertainment platform and marketing gimmick. Consequently, interest has ebbed and flowed with very little research into its effectiveness as a tool for learning. Thanks to recent advances in technology making it more accessible to both creators and users of content, researchers are now making steady progress in studying how stereoscopy affects learning. Dozens of empirical papers have been published in the last decade about the impact of stereoscopy on learning. As a result, a corpus of research now points to a coherent message about how, when, and where stereoscopy can be most effective in supporting science education.

This position paper synthesizes the results of those studies with examples from three studies recently completed and published by the authors. The first study focused on the impact of stereoscopy on the ability of middle-school aged children to process spatial cognition tasks related to drawings of a Mars rover (Price \& Lee, 2010). The second study assessed how young children process static stereoscopic images about scientific objects and phenomena at various scales (Price, Lee \& Malatesta, 2014). The third study focused on adults watching a highdefinition stereoscopic film on the structure and modeling of the Milky Way galaxy (Price, Lee, Kasal, SubbaRao \& Aguillera, in press). Implications are discussed at the end of this paper for both science educators and science visualization developers. 


\section{Recent Trends in Stereoscopy in Science Education}

The earliest documented application of stereoscopy to science education dates back to 1838. An English physicist and inventor, Sir Charles Wheatstone, designed the first stereoscope to illustrate how binocular parallax works in the human vision system (Wheatstone, 1838). Following his invention, he published a commentary about how the stereoscope could be used for science education (Wheatstone, 1852). A comprehensive review on the subsequent early history of stereoscopic technology was conducted by Zone (2014). It describes mostly minor, yet steady technological progress made from early applications up to the invention of stereoscopic film technology. After that point, stereoscopy was most often used as an entertainment technology and marketing gimmick. As such, interest in stereoscopy varied as new gimmicks would emerge and then lose their novelty over time (Gurevitch \& Ross, 2013).

That inconsistent pattern of public interest continues today as blockbuster movies such as 2009's Avatar, currently the highest grossing film of all time, reignited tremendous interest which now shows signs of declining. A normalized plot of Google search activity for "stereoscopic 3D" shows interest initially driven by Avatar and then fading (Figure 1). Further evidence suggests that today's resurgence of 3D films may be another fad as sales of 3D film tickets have declined four years in a row in total revenue and seven years in a row in percentage of overall ticket sales (Lieberman, 2014), and sales of stereoscopic home theater systems have fallen below industry expectations (Dash, 2013).

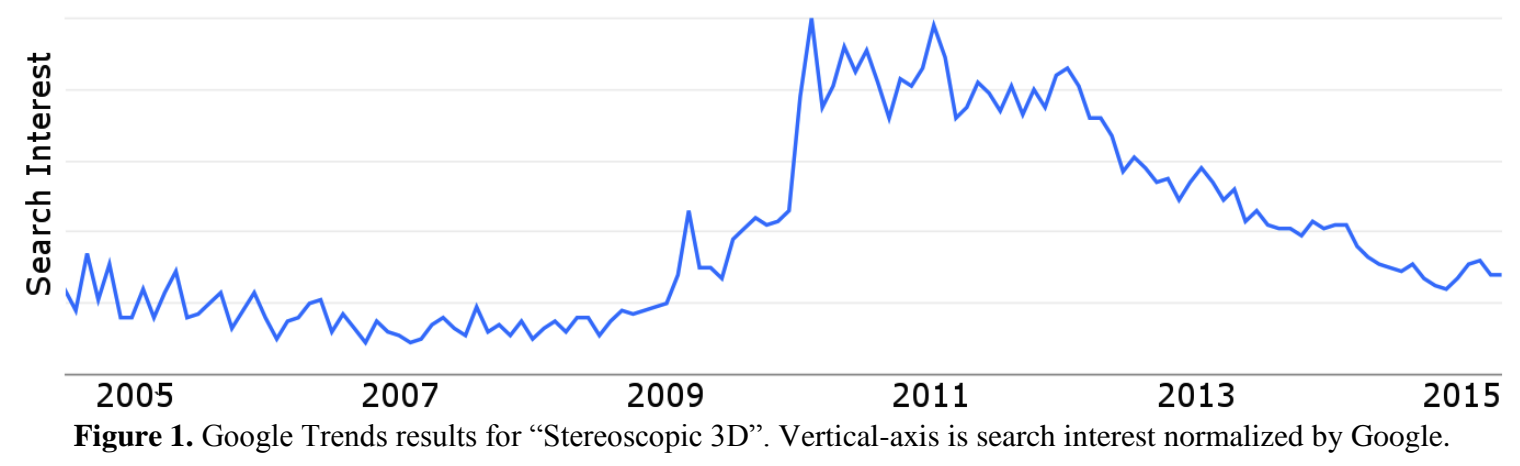

However, there are reasons to believe that the use of stereoscopy as a tool for general science education is still worth considering. The first is the rapid decrease in the cost to produce and present stereoscopic content. Thanks to technology advances such as the GeoWall (Johnson, Leigh, Morin \& Van Keken, 2006) and consumer level stereoscopic video displays, high quality and portable stereoscopic visualization systems can be built for less than a thousand dollars. Moreover, the production of affordable, consumer level stereoscopic cameras and software to create stereoscopic visualizations using devices as ubiquitous as mobile phones has made it easier to create content (White, 2010). This puts content creation and use in the hands of educators and does not require an industry to support it. At the same time, children who live in a world where stereoscopic media are commonplace are coming to expect highly immersive visualizations to pique their interest. In addition, the growth of informal science education as an alternative source for science learning (Feder, Shouse, Lewenstein, \& Bell, 2009; Falk \& Dierking, 2010) makes stereoscopic media a fertile ground for developing content that is engaging and informative, not to mention that the public already associates the media with informal settings such as museums and science centers (Steinbach, 2011). Finally, virtual and augmented reality technologies, such as Oculus Rift, continue to gain popularity as science education tools (Turner, Holmes, \& Gordon, 2014). They often integrate stereoscopic visualizations, so what we learn about stereoscopic learning can have an important role in determining how to use these new technologies.

As with many learning technologies, stereoscopy has been attributed to generating a wide range of learning outcomes to varied extents (McIntire, Havig \& Geiselman, 2014; McMahon \& Garrett, 2014). However, in more recent years the scholarship on stereoscopy has found limited impacts of stereoscopy when applied to STEM education. For instance, Cliburn and Krantz (2008) found no stereoscopic advantage in the ability to identify objects in a virtual reality simulation. Cid and Lopez (2010) found no stereoscopic advantage in learning about phases of the 
Moon. Joseph (2011) found no advantage in learning about galaxy distribution. Mukai, Yamagishi, Hirayama, Tsuruoka \& Yamamoto (2011) found no advantage in learning about basic computer hardware engineering. Seabra \& Santos (2009) found no advantage in learning descriptive geometry. And McDermott, Hurmas, Slocum, Halfen, and White, et al. (2012) found no difference between stereoscopic and 2D visualizations in learning about physical geography.

\section{RESULTS}

These studies indicate a limited impact of stereoscopy when designed to replace visualizations used in typical science classrooms across a wide variety of STEM domains. However, our research suggests that, instead of using stereoscopy for simple replacement of typical visualizations, careful implementations and targeted research designs are necessary to probe the impact of stereoscopy on more nuanced learning outcomes. Indeed, in our own studies we found stereoscopy to have little to no advantage on typical learning outcomes such as task accuracy or time on task when stereoscopic visualizations were used in simple tasks such as memory, block rotation, and letter rotation tasks (Price, et al., 2010). It was only when using more carefully designed visualizations and complex measures that we uncovered significant learning benefits associated with the use of stereoscopy. In one study, we found no stereoscopic advantage to how young children answered multiple-choice questions about spatial properties of an image. However, the children did show a difference in the level of details depicted in their drawings after seeing stereoscopic images as compared to static ones (Price, et al. 2014). In another study of adults watching a film on modeling of the Milky Way galaxy structure, we found no stereoscopic vs. 2D difference in the viewers' performance on an immediate post-test after controlling for pre-test performance. But we did find that the stereoscopic group recalled significantly more accurate information of what they learned from the film when tested six months later (Price, et al., in press). We are not presently aware of any other studies on the long-term effects of stereoscopy on learning outcomes. Stereoscopy can preferentially enhance the viewer's long-term learning of objects with highly spatially complicated features by increasing cognitive resources dedicated to storage. According to the Limited Capacity Model (Lang, 2000), this is accomplished through both increased focus on the spatial elements as well as increased viewer motivation - ostensibly because they felt more immersed in, connected to and focused on the visualization as compared to typical two-dimensional visualizations.

\section{Spatial Cognition}

Stereoscopic technology is often used to support learning in highly spatial domains. It is used in the training of pilots (Menendez \& Bernard, 2000), surgeons (van Beurden, IJsselsteijn, \& Juola, 2012) and drivers (De Winter, Wieringa, Dankelman, Mulder, Van Paassen, et al., 2007) - all professions where attention to spatial detail is critical to safety. In science, it has often been used to support learning of astronomy (Cid \& Lopez, 2010; Joseph, 2011), geography (McDermott, et al., 2012), geology (Johnson, et al., 2006), and geophysics (Halfen, White, Slocum, Hirmas \& McDermott, 2014). In fact, the most popular implementation of stereoscopy for education is through the aforementioned GeoWall - a low cost tool for projecting stereoscopic images using a computer and two data projectors - that has been installed in hundreds of formal and informal educational settings and used primarily for earth science education, training and research.

Stereoscopy is more often used in highly spatial domains because of its additional information about depth. It enhances a viewer's ability to perceive structure of an object along an axis perpendicular to the image plane. However, it may also have an indirect, yet equally as important, impact on overall cognitive efforts a viewer needs to perceive the object and later recall it. The type and level of information the brain perceives may alter how the brain processes the rest of the visualization, which has implications for aspects of the visualization that may be competing for cognitive resources. Cognitive load theory assumes that working memory, which deals with novel information accessed through interactions with the world, has a limited capacity to process both auditory and visual (2D and 3D) information; on the other hand, working memory can easily process information already stored in longterm memory (Sweller, Merrienboer, \& Paas, 1998). Stereoscopy can increase (Kooi \& Toet 2004) or decrease (Nemire, 1998) cognitive load of the viewer, depending on how it is implemented. By relieving the mind of the burden of interpreting depth from secondary cues (such as shadows) to process a 3D structure presented in a 2D format, stereoscopy may free up cognitive resources for the viewer to carry out other cognitive functions. 
One accepted measure of cognitive load is time on task, i.e. how long it takes for a person to conduct a task (Paas, Tuovinen, Tabbers \& Van Gerven, 2003). In our study with early adolescents (Price, et al., 2010), we found that a significantly more time was needed to solve stereoscopically presented spatial cognition tasks without improvement in accuracy as compared with solving the same tasks presented in 2D. This delay effect with stereoscopic visualizations was reproduced in a similar experiment by Ting, Tan, West, Squelch \& Foster (2011). In our study with younger children (Price, et al., 2014), we found no difference in the amount of time it took for children to answer questions about stereoscopic or 2D images. In our third study, we also found no difference in the amount of time it took adults to respond to a test after watching a film in either 2D or stereo (Price,, et al., in press). The difference in those results can be attributed to the fact that the latter studies involved more complex learning tasks, while the former more simple tasks involving the mental rotation of objects. The difference in processing time is related to mental rotation but is lost in the more complex reasoning involved with learning tasks.

Stereoscopy's impact on cognitive load can be mediated by the viewer's spatial ability. In our studies about scientific imagery and film, we measured the mental visualization ability of participants. In both studies, differences in performance between stereoscopic and 2D visualizations were significantly positively correlated with the participants' spatial cognition scores. Others have also found a relationship between spatial ability and ability to interpret stereoscopic images (Huk, 2006; McIntire, et al., 2014; Keebler, 2011; Vendeland \& Regenbrecht, 2013). However, Barrett \& Hegarty (2014) found stereoscopy may preferentially benefit low spatial learners, particularly when applied to simpler visualizations. Mitsuya, Kawai, Sato, Yamagata, Yamazaki, et al. (2009) also found that stereoscopy helped children with developmental dyslexia learn to write hiragana characters. Spatial ability has been found to be a predictor for future success in science and entry into science careers (Wai et al., 2009), which boosts stereoscopy's potential in improving science education for all learners.

\section{Novelty}

When pilot testing stereoscopic visualizations and related earth science assessments in a STEM-focused middle school, we noticed that the students were very excited about the process of wearing stereoscopic glasses. Some students extended their hands in front of the glasses and said "Oh, cool!" while moving them back and forth even though the stereoscopic equipment was not yet turned on. Clearly, stereoscopy is still seen as a novel tool - at least in formal school settings where most visualization media are almost always in 2D. Whether and how to control for this novelty in estimating the impact of stereoscopy on learning can be a matter of debate. Novelty can be an inherent part of the process that should be included in any authentic experiment. However, over time the novelty inherent in stereoscopy will eventually diminish as stereoscopic visualizations become more and more prevalent in society (indeed, it is often cited as the reason behind the recent decline in 3D films' box office performance). And at an operational level the novelty effect can quickly wear off during an extended activity as the learner gets used to the experience. Novelty has many implications for affecting cognition through heightened task engagement. Bunzeck \& Düzel (2006) identified a region in the mid brain as being the source of extra interest and learning caused by novelty. They speculate the cause is due to increased dopamine levels associated with the introduction of a new stimulus or element. This increase may not be sustained indefinitely as the stimulus or element becomes too familiar to the viewer over time, thus causing any impacts associated with novelty on learning to diminish accordingly.

Novelty is also seen as an additional source of cognitive load (Orion, 2007) and may be responsible for some of the gender differences seen in learning at science centers (Kubota \& Olstead, 1991). In our extended review of the empirical literature on stereoscopy, we found no studies where the novelty effect was controlled in research design or data analysis. For each of our studies, we attempted to mitigate or control for the novelty effect. We used diverse techniques such as (1) measuring prior exposure to stereoscopic visualizations to gauge the viewer's familiarity with stereoscopy, (2) providing participants with a substantial number of training activities as well as time to become accustomed to the stereoscopic visualizations in use, and (3) in our stereoscopic slide study, all of our participants wore stereoscopic glasses regardless of whether the visualization they were looking at was in stereo or $2 \mathrm{D}$. We encourage all other researchers to make creative and serious efforts to limit or measure the impact of novelty on their studies. Not doing so runs the risk of overestimating stereoscopic media effects (Mitchell, 2012). 


\section{Implications}

The main implications of recent research results in the field of stereoscopy in education can be summarized in two ways. First, use stereoscopic visualizations only for the content that needs it. Second, if the use of stereoscopy is deemed to be beneficial, then design stereoscopic visualizations in the context of learning activities where the visualizations will be used.

Stereoscopy should be matched with content that is not only highly spatial in nature, but also in which depth perception is critical in perceiving and understanding content. The decision to use stereoscopy should be tightly interwoven with objectives of proposed learning activities (Bendis, 2003) so that stereoscopy is not being used to teach concepts that don't require a sense of depth. For example, when teaching which route for an airplane to take to fly from New York to Shanghai, a stereoscopic visualization can help show how a route plotted on a sphere is shorter than one plotted on a flat, planar surface (like a map). The fact that the Earth is a sphere becomes a salient and critical information when seen stereoscopically, while it is taken for granted but rarely elicited when viewing 2D maps. Dynamic visualizations work best when the salient features of the visualization are emphasized (McElhaney, Chang, Chiu \& Linn, 2015). This is especially evident when viewing dense structures where stereoscopy can help discern between foreground and background objects such as dense data graphs (Alper, Hollerer, Kuchera-Morin, \& Forbes, 2011) and dense star fields (Fairall, 2005).

Stereoscopy should also be carefully implemented. In our study of the stereoscopic film, we presented a set of four Stereoscopic Design Principles to increase the educational impact of stereoscopic visualizations. They are derived from two sources: decades of prior experience developing educational stereoscopic visualizations and a comprehensive review of hundreds of spatial cognition and stereoscopic literature, including 38 empirical papers on the design and impact of stereoscopy in education. While originally intended for film developers, these principles can be applied to a wide variety of stereoscopic media.

The principles are:

- $\quad$ Gradually Adjust Viewers to the Presentation

- $\quad$ Respect Stereo Discipline (use stereo only when needed)

- $\quad$ Utilize Pictorial Depth Cues and

- $\quad$ Minimize Other Sources of Cognitive Load.

Application of the stereoscopic design principles can help focus the visualization on the features associated with depth and also prepare the viewer gradually to think in three dimensions. Recent studies have shown that viewers of stereoscopic content often still think of the content in two dimensions, perhaps because they are primed by experience (through books, television, etc.) to do the mental translations needed to convert 2D visualizations into a 3D space (Price, et al., 2010; Ting, et al., 2011). Providing the audience with a period to get used to the stereoscopy can minimize this effect. For example, do not begin a visualization with a striking, "in-your-face", visual but instead ease them into it. Also, because stereoscopy increases cognitive load, it is important to find ways to minimize other sources of cognitive load - which implies the creation of visualizations that are clear and focused with minimal extraneous content. For example, limit extraneous narration and the detail of imagery not needed to convey the depth-related concepts behind the visualization.

Stereoscopy should not be used solely as a gimmick in educational applications. First, the novelty may interfere with the learning goals by creating distractions and increasing cognitive load. Second, any learning outcomes resulting from the temporarily increased engagement may fade along with the novelty. We believe this is one reason why earlier studies were more positive in the impact of stereoscopic visualizations than recent studies. Or, if stereoscopy is new to the audience, wait until they are more comfortable with the technology before introducing the core learning concepts of the learning activity with stereoscopy.

Despite its limits, stereoscopy may still be of use to educators of astronomy and the earth sciences - two of the most highly spatial fields of science (Plummer, 2014; Ishikawa \& Kastens, 2005). Astronomy has an especially difficult educational challenge in that astronomical objects are inherently 3D in nature with no flat planes to use as a 
frame of reference. Also, its objects of study are so far away that stereoscopic photographs (from Earth) are impossible to create. Thus, students never get to see what they are studying in three dimensions: a star in a telescope will always look like a point source and an outer planet will always appear as a disc. Stereoscopy can provide students their only opportunity to experience a three dimensional structure of astronomical systems through physiologically-based sense of depth. It is also very popular in planetarium settings (Fairall, 2005; Shiomi, Shoichi, Hidehiko, Mario, , José, et al., 2014; Aguilera, 2015)

Stereoscopy has long been a staple of earth science education as well (Kuenen, 1950). This is especially true in geology, where structural details are important at both very small (e.g.: sedimentation) and very large (e.g.: continental) scales. Stereoscopy also has applications in other areas of earth science such as meteorology (Muller, Denis, Dundas, Mitchell, Naud, et al., 2007), oceanography (Harvey, Shortis, Stadler, \& Cappo, 2002) and volcanology (Yamashina, Matsushima, \& Ohmi, 1999). Field experience is important to all of these earth science disciplines, yet it is not always available to students. In these cases, stereoscopy may be the next best method to facilitate learning when applied carefully.

\section{CONCLUSION}

While standalone studies are often the vanguard of research in new fields, by themselves they present limited value to designers of visualizations and developers of curriculum materials (Warschauer, M., Duncan, G. J., \& Eccles, 2015). In this position paper, we have synthesized our research in stereoscopy with recent empirical studies from literature in order to initiate a dialogue between the readers of this paper and literature. Results of the synthesis point towards generally limited successful uses of stereoscopic media in science education with a pocket of potentially beneficial applications. Our position is that stereoscopy should be used only where its unique properties can accommodate specific requirements of understanding topics and tasks- namely visualizations of complex objects and phenomena where the spatial sense of depth is germane to conveying the core ideas that the visualization entails. More research is needed on the effect of novelty, long-term learning and possible learning differences between the various methods of implementing stereoscopy.

\section{ACKNOWLEDGEMENTS}

This manuscript, and much of the author's prior work in this field, was funded by National Science Foundation award DRL-1114645 and supported by the American Association of Variable Star Observers under the direction of Dr. Arne Henden and Dr. Stella Kafka.

\section{AUTHOR INFORMATION}

\section{Aaron Price}

Dr. Price is the Manager of Evaluation and Research at the Museum of Science and Industry, Chicago where he leads a team of five who study the impact of the Museum's programming on the community. He worked 14 years for an astronomical citizen science organization before joining the Museum. He is a PI of two National Science Foundation projects studying citizen science and science visualizations. E-mail: aaron.price@msichicago.org (Corresponding author)

\section{Hee-Sun Lee}

Dr. Lee specializes in science education, assessment of curricula, and development of technology-enhanced curricula. E-mail: hlee@ concord.org

\section{Julia D. Plummer}

Dr. Plummer is an Associate Professor of Science Education at Pennsylvania State University. Prior to this role, she spent more than a decade teaching children and adults in planetariums. Her research interests focus on how children and adults engage in scientific practices in the domain of astronomy. This includes investigating both formal and informal learning environments, the role of curriculum and professional development in educators' beliefs, and the importance of spatial reasoning to the domain. E-mail: jdp17@psu.edu 


\section{Mark SubbaRao}

Dr. SubbaRao is the Director of the Space Visualization Laboratory at the Adler Planetarium. He uses scientific visualization and 3D computer graphics as tools to make complex scientific concepts, such as the 3D structure of the Universe, accessible to the public. E-mail: msubbarao@adlerplanetarium.org

\section{Ryan Wyatt}

As Director of Morrison Planetarium at the California Academy of Sciences, Ryan Wyatt oversees the largest alldigital fulldome planetarium in the world that uses real data and revolutionary technologies to transform the way Earth-bound audiences experience the universe. E-mail: rwyatt@calacademy.org

\section{REFERENCES}

Aguilera, J. C. (2015, March). Composing a model of outer space through virtual experiences. In IS\&T/SPIE Electronic Imaging (pp. 939205-939205). International Society for Optics and Photonics.

Alper, B., Hollerer, T., Kuchera-Morin, J., \& Forbes, A. (2011). Stereoscopic highlighting: 2d graph visualization on stereo displays. Visualization and Computer Graphics, IEEE Transactions on, 17(12), 2325-2333.

Barrett, T. J., \& Hegarty, M. (2014). Interaction design and the role of spatial ability in moderating virtual molecule manipulation performance. In Proceedings of the 36th Annual Conference of the Cognitive Science Society (pp. 672-677). Cognitive Science Society Austin, TX.

Bendis, J.E. (2003). A history and future of stereoscopy in education. http://jaredjared.com/wpcontent/uploads/2011/10/Bendis-Stereoscopy.pdf

Bunzeck, N., \& Düzel, E. (2006). Absolute coding of stimulus novelty in the human substantia nigra/VTA. Neuron, 51(3), 369-379.

Cid, X. C., \& Lopez, R. E. (2010). The impact of stereo display on student understanding of phases of the moon. Astronomy Education Review, 9(1), 010105.

Cliburn, D., \& Krantz, J. (2008). Towards an effective low-cost virtual reality display system for education. Journal of Computing Sciences in Colleges, 23(3), 147-153.

Devernay, F., \& Beardsley, P. (2010). Stereoscopic cinema. In Image and Geometry processing for 3-D cinematography (pp. 11-51). Berlin: Springer Berlin Heidelberg.

De Winter, J. C. F., Wieringa, P. A., Dankelman, J., Mulder, M., Van Paassen, M. M., \& De Groot, S. (2007). Driving simulator fidelity and training effectiveness. In Proceedings of the 26th European annual conference on human decision making and manual control, Lyngby, Denmark.

Fairall, A. (2005, June 14-17). Seeing beyond the naked eye in a planetarium. Paper presented at Communicating Astronomy with the Public, Munich, Germany.

Falk, J. H., \& Dierking, L. D. (2010). The 95 Percent Solution School is not where most Americans learn most of their science. American Scientist, 98(6), 486-493.

Feder, M. A., Shouse, A. W., Lewenstein, B., \& Bell, P. (Eds.). (2009). Learning Science in Informal Environments: People, Places, and Pursuits. National Academies Press.

Gurevitch, L., \& Ross, M. (2013). Stereoscopic media: Scholarship beyond booms and busts. Public, 24(47), 83-93.

Halfen, A. F., White, T., Slocum, T., Hirmas, D. R., McDermott, D., Atchley, P., ... \& Gilbreath, A. (2014). A New Stereoscopic (3D) Media Database and Teaching Strategy for Use in Large-Lecture Introductory Geoscience Courses. Journal of Geoscience Education, 62(3), 515-531.

Harvey, E., Shortis, M., Stadler, M., \& Cappo, M. (2002). A comparison of the accuracy and precision of measurements from single and stereo-video systems. Marine Technology Society Journal, 36(2), 38-49.

Huk, T. (2006). Who benefits from learning with 3D models? The case of spatial ability. Journal of Computer Assisted Learning, 22(6), 392-404.

Ishikawa, T. \& Kastens, K.A. (2005). Why some students have trouble with maps and other spatial representations. Journal of Geoscience Education, 53, 184-197.

Johnson, A., Leigh, J., Morin, P., \& Van Keken, P. (2006). GeoWall: stereoscopic visualization for geoscience research and education. Computer Graphics and Applications, IEEE, 26(6), 10-14.

Joseph, N. M. (2011). Stereoscopic visualization as a tool for learning astronomy concepts. (Doctoral dissertation, Purdue University Purdue, Indiana).

Kain, E. (2013). CES 2013: 3D TV Is Dead, Long Live 4K. Forbes, January 10, 2013. http://www.forbes.com/sites/erikkain/2013/01/10/ces-2013-3d-tv-is-dead-long-live-4k/ 
Keebler, J. R. (2011). Effects of 3D Stereoscopy, Visuo-spatial Working Memory, and Perceptions of Simulation Experience on the Memorization of Confusable Objects (Doctoral dissertation, University of Central Florida Orlando, Florida).

Kooi F.L. \& Toet A. (2004) Visual comfort of binocular and 3D displays. Displays, 25(2), 99-108.

Kubota, C. A., \& Olstad, R. G. (1991). Effects of novelty-reducing preparation on exploratory behavior and cognitive learning in a science museum setting. Journal of research in Science Teaching, 28(3), 225-234.

Kuenen, P. H. (1950). Stereoscopic projection for demonstration in geology, geomorphology, and other natural sciences. The Journal of Geology, 49-54.

Lang, A. (2000). The limited capacity model of motivated mediated message processing. Journal of Communication, 50(1), 46-70.

Lieberman, D. (2014). 2014 Box Office will be hurt by diminishing popularity of $3 \mathrm{~d}$ movies: analyst. Deadline, February 3, 2014.

McDermott, D., Hirmas, D., Slocum, T., Halfen, A., White, T., Egbert, S., Atchley, P.,Johnson, W. \& Gilbreath, A. (2012). Do stereoscopic displays improve learning in introductory physical geography classes?. Proceedings - AutoCarto 2012 Columbus, Ohio, USA September 16-18, 2012

McElhaney, K. W., Chang, H. Y., Chiu, J. L., \& Linn, M. C. (2014). Evidence for effective uses of dynamic visualisations in science curriculum materials. Studies in Science Education, 51(1), 1-37.

McIntire, J. P., Havig, P. R., \& Geiselman, E. E. (2014). Stereoscopic 3D displays and human performance: A comprehensive review. Displays, 35(1), 18-26.

McMahon, M. T., \& Garrett, M. (2014). Applications of Binocular Parallax Stereoscopic Displays for Tasks Involving Spatial Cognition in 3D Virtual Environments. International Journal of Gaming and ComputerMediated Simulations (IJGCMS), 6(4), 17-33.

Menendez, R. G., \& Bernard, J. E. (2000, October 7-13). Flight simulation in synthetic environments. Paper presented at Digital Avionics Systems Conference, 2000 Proceedings. Retrieved June 22, 2014 from IEEE Xplore.

Mitchell, W. (25 March, 2012). As 3D Novelty wears off, some experts call for more extreme uses. Screen Daily.

Mukai, A., Yamagishi, Y., Hirayama, M. J., Tsuruoka, T., \& Yamamoto, T. (2011). Effects of Stereoscopic 3D Contents on the Process of Learning to Build a Handmade PC. Knowledge Management \& E-Learning: An International Journal (KM\&EL), 3(3), 491-506.

Muller, J. P., Denis, M. A., Dundas, R. D., Mitchell, K. L., Naud, C., \& Mannstein, H. (2007). Stereo cloud- top heights and cloud fraction retrieval from ATSR-2. International Journal of Remote Sensing, 28(9), 19211938.

National Research Council (NRC). (2006). Learning to think spatially. Washington, DC: National Academies Press.

Nemire K (1998) Enhancing cockpit design with an immersive virtual environment rapid prototyping and simulation system. Proc SPIE 3363:112-123

Orion, N. (2007). A holistic approach for science education for all. Eurasia Journal of Mathematics, Science \& Technology Education, 3(2), 111-118.

Paas F, Tuovinen JE, Tabbers H, Van Gerven PW (2003) Cognitive load measurement as a means to advance cognitive load theory. Educational Psychologist, 38(1):63-71

Plummer, J. D. (2014). Spatial thinking as the dimension of progress in an astronomy learning progression. Studies in Science Education, 50(1), 1-45.

Price, A., \& Lee, H. S. (2010). The effect of two-dimensional and stereoscopic presentation on middle school students' performance of spatial cognition tasks. Journal of Science Education and Technology, 19(1), 90103.

Price, C. A., Lee, H. S., \& Malatesta, K. (2014). Stereoscopy in Static Scientific Imagery in an Informal Education Setting: Does It Matter?. Journal of Science Education and Technology, 23(6), 721-734.

Price, C.A., Lee, H.-S., Kasal, E., SubbaRao, M., \& Aguillera, J. (in press). Comparing Short and Long-term Learning Effects between Stereoscopic and 2-Dimensional Film at a Planetarium. Science Education.

Seabra, R. D., \& Santos, E. T. (November 5-7, 2009). Exploring Virtual Reality in Classroom for Teaching and Learning of Descriptive Geometry. Paper presented at Interactive Computer Aided Blended Learning 2009 conference, Florianopilis, Brazil.

Shiomi, N., Shoichi, I., Hidehiko, A., Mario, Z., José, I., Edwin, C., ... \& Tsunehiko, K. (2014). Stereoscopic 3D Projections with MITAKA An Important Tool to Get People Interested in Astronomy and Space Science in Peru. Sun and Geosphere, 9, 115-116. 
Slocum, T., Halfen, A., White, T., Hirmas, D., Egbert, S., McDermott, D., \& Johnson, W. (2011). Adoption of Stereoscopic Displays in Geographic Education: A Persistent Problem in Geographic Visualization.

Steinbach, L. (2011). 3D or Not 3D? Is that a Question?. Curator: The Museum Journal, 54(1), 41-54.

Sweller, J., Van Merrienboer, J. J., \& Paas, F. G. (1998). Cognitive architecture and instructional design. Educational psychology review, 10(3), 251-296.

Ting, S., Tan, T., West, G., Squelch, A., \& Foster, J. (2011, November 6-9). Quantitative assessment of 2D versus 3D visualization modalities. In Visual Communications and Image Processing, 2011. Retrieved from IEEE Xplore.

Turner, S., Holmes, N., \& Gordon, A. (June 9-15, 2014) Immersive technology devices and field work: Oculus Rift. Paper presented at Universities Week Ideas for Life. Retrieved from http://www.researchgate.net/profile/Scott_Turner4/publication/263086425_Immersive_technology_devices _and_field_work_Oculus_Rift/links/00b49539c6c8d9056e000000.pdf

Van Beurden, M. H. P. H., IJsselsteijn, W. A., \& Juola, J. F. (2012). Effectiveness of stereoscopic displays in medicine: a review. $3 D$ Research, $3(1), 1-13$.

Vendeland, J. \& Regenbrecht, H. (2013). Is there any Use in Stereoscopic Slide Presentations?. ACM CHINZ '13, November 15-16, 2013, Christchurch, New Zealand.,

Wai, J., Lubinski, D., \& Benbow, C. P. (2009). Spatial ability for STEM domains: Aligning over 50 years of cumulative psychological knowledge solidifies its importance. Journal of Educational Psychology, 101, 817-835.

Warschauer, M., Duncan, G. J., \& Eccles, J. S. (2014). Inaugural Editorial: What We Mean by “Open”. DOI: $10.1177 / 2332858414556274$

Wheatstone, C. (1838). Contributions to the physiology of vision.--Part the first. On some remarkable, and hitherto unobserved, phenomena of binocular vision. Philosophical transactions of the Royal Society of London, 371-394.

Wheatstone C (1852) Contributions to the physiology of vision: part the second. On some remarkable, and hitherto unobserved, phenomena of binocular vision. Philosophical transactions of the Royal Society of London, $142: 1-17$

White, I. (2010). A simple, low- cost stereographic video capture and viewing solution for teaching psychomotor skills using online delivery. British Journal of Educational Technology, 41(3), 420-431.

Yamashina, K. I., Matsushima, T., \& Ohmi, S. (1999). Volcanic deformation at Unzen, Japan, visualized by a timedifferential stereoscopy. Journal of volcanology and geothermal research, 89(1), 73-80.

Zone, R. (2014). Stereoscopic Cinema and the Origins of 3-D Film, 1838-1952. University Press of Kentucky. Lexington, KY. 


\section{NOTES}

